\section{Colloid carcinoma of the minor duodenal papilla}

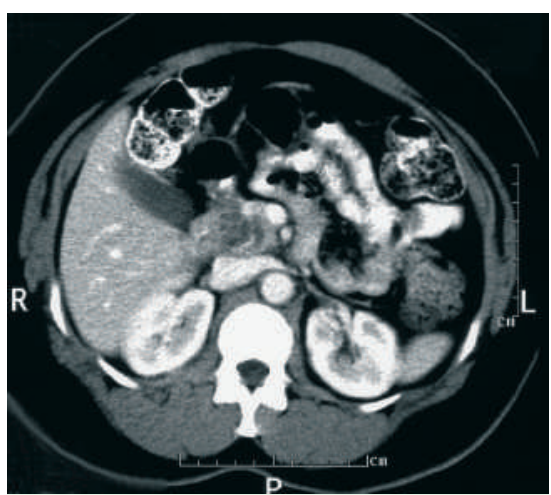

Figure 1 Computed tomography showing cystic mass in the head of the pancreas.

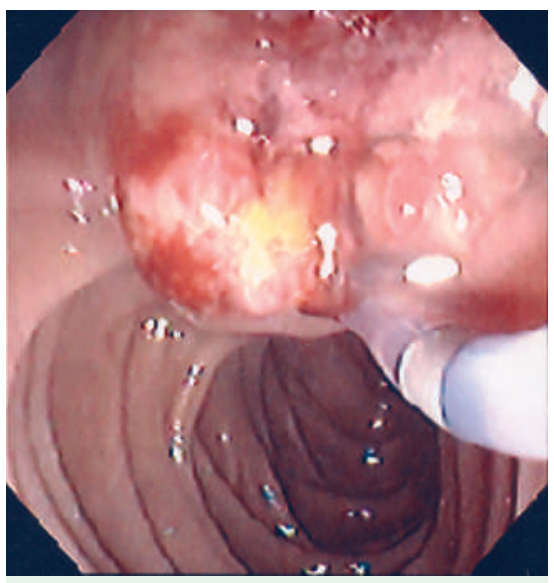

Figure 2 Ulcerated, polypoid mass at the minor duodenal papilla.

A 43-year-old woman presented with intermittent epigastric pain and nausea. Her hemoglobin concentration was $10.3 \mathrm{~g} / \mathrm{dL}$. Abdominal imaging revealed a $4-\mathrm{cm}$ cystic mass in the pancreatic head ( $\odot$ Figure 1). ERCP showed an ulcerated polypoid mass at the minor duodenal papilla ( $\odot$ Figure 2). Cannulation of the normal-appearing major papilla showed a dilated, 4-mm main pancreatic duct and a stricture of the main duct in the head of the gland ( $\bullet$ Figure 3 ). Cannulation through the mass showed contrast in the ectatic dorsal pancreatic duct, which confirmed involvement of the minor papilla by tumor. Pancreas divisum was not present. A pancreaticoduodenectomy (Whipple procedure) revealed a polypoid gelatinous mass measuring $3 \times 2 \times 1.5 \mathrm{~cm}$ protruding from the minor papilla. Histologically the tumor showed mucin pools containing malignant epithelial cells ( $\bullet$ Figure 4). Resection margins and 15 peripan-

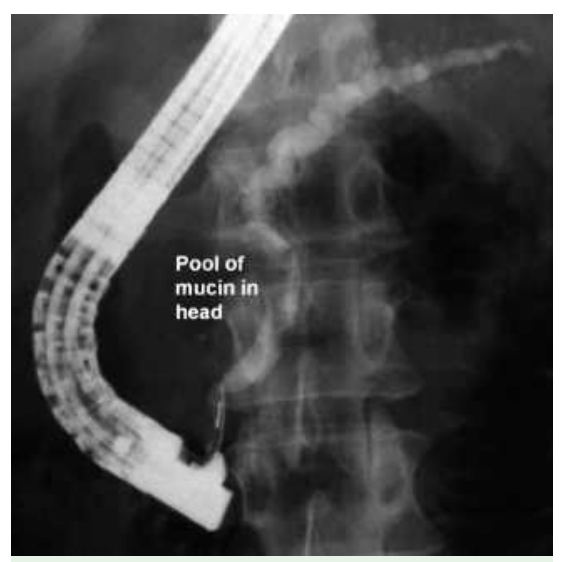

Figure 3 Stricture of the proximal duct of Wirsung seen at ERCP.

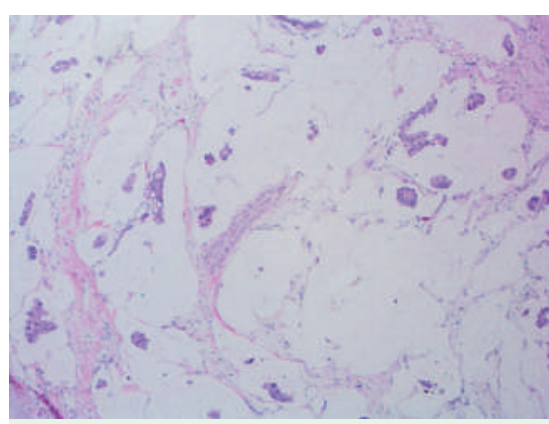

Figure 4 Histological appearance of the tumor with pools of mucin containing scant malignant glandular epithelial cells. (H\&E; original magnification $\times 20$ ).

creatic lymph nodes were free of tumor. Despite an uncomplicated immediate postoperative course, CA 19-9 levels are rising 22 months later along with possible liver metastases.

Tumors of the minor papilla are uncommon, but carcinoid tumors [1], somatostatinomas [2], and a case of a nonendocrine ductal adenocarcinoma [3] have been reported. Reasons for the rarity of recorded tumors in this location may be a low incidence but also the lack of symptoms caused by small indolent endocrine neoplasms and the absence of jaundice owing to patency of the major papilla [3]. Aggressive neoplasms may overgrow adjacent structures, thus obscuring their origin at the minor papilla [3]. Mucinous noncystic (colloid) carcinoma of the pancreas represents only $1 \%-2 \%$ of all pancreatic nonendocrine neoplasms $[4,5]$ and has not been described in the minor papilla previously. It is characterized his- tologically by extracellular mucin lakes with "floating" malignant epithelial cells $[4,5]$. It is important to distinguish colloid carcinoma from mucin-producing adenocarcinoma, signet-ring cell carcinoma and mucinous cystic neoplasms because the prognosis of colloid carcinoma is significantly better than that of ordinary pancreatic ductal adenocarcinoma, with a 5 -year survival rate of $57 \%[4,5]$.

Endoscopy_UCTN_Code_CCL_1AB_2AZ_3AB

H. Varnholt ${ }^{1,4}$, R. B. Wait ${ }^{2}$, J. D. Mueller ${ }^{1}$, D. J. Desilets ${ }^{3}$

Department of Pathology, Baystate Medical Center, Tufts University School of Medicine, Springfield, Massachusetts, USA

2 Department of Surgery, Baystate Medical Center, Tufts University School of Medicine, Springfield, Massachusetts, USA

3 Department of Gastroenterology, Baystate Medical Center, Tufts University School of Medicine, Springfield, Massachusetts, USA

${ }^{4}$ Department of Pathology, University of Cologne, Germany

\section{References}

1 Noda Y, Watanabe H, Iwafuchi M, Furuta Ket al. Carcinoids and endocrine cell micronests of the minor and major duodenal papillae. Their incidence and characteristics. Cancer 1992; 70: 1825-1833

2 Malone MJ, Silverman ML, Braasch JW et al. Early somatostatinoma of the duct of Santorini. Arch Surg 1985; 120: 1381 - 1383

3 YamaoK, Ohhashi K, Furukawa Tet al.Primary carcinoma of the duodenal minor papilla. Gastrointest Endosc 1998; 48: 634-636

4 Adsay NV, Pierson C, Sarkar F et al. Colloid (mucinous noncystic) carcinoma of the pancreas. Am J Surg Pathol 2001; 25: 26 - 42

5 Whang EE, Danial T, Dunn JC et al. The spectrum of mucin-producing adenocarcinoma of the pancreas. Pancreas 2000; 21: 147-151

Bibliography

DOI 10.1055/s-2007-966565

Endoscopy 2007; 39: E221

(c) Georg Thieme Verlag KG Stuttgart · New York . ISSN 0013-726X

\section{Corresponding author}

\section{J. Desilets, MD, PhD}

Department of Medicine

Division of Gastroenterology

Baystate Medical Center

Tufts University School of Medicine

759 Chestnut Street

Springfield

MA 01199

USA

Fax: +1-413-794-8828

david.desilets@bhs.org 